\begin{tabular}{cc|c}
\hline Tar. Bil. Der. & Tarım Bilimleri Dergisi & Journal of Agricultural Sciences \\
& $\begin{array}{c}\text { Dergi web sayfası: } \\
\text { www.agri.ankara.edu.tr/dergi }\end{array}$ & Journal homepage: \\
& www.agri.ankara.edu.tr/journal
\end{tabular}

\title{
Tansiyometrik Nem Potansiyelinin Yüzey Altı Drenajlı Ağır Killi Toprakta Mevsimsel Yağışlara Bağlı Dağılımı
}

\author{
Rifat AKIŞa \\ ${ }^{a}$ Mustafa Kemal Üniversitesi, Ziraat Fakültesi, Toprak Bilimi ve Bitki Besleme Bölümü, Hatay, TÜRKIYE
}

\section{ESER BILGISII}

Araştırma Makalesi

DOI: 10.1501/Tarimbil_0000001305

Sorumlu Yazar: Rifat AKIŞ, E-posta: akiskoy@gmail.com, Tel: +90 (326) 2455836

Geliş Tarihi: 26 Ocak 2013, Düzeltmelerin Gelişi: 24 Mart 2014, Kabul: 1 Nisan 2014

\begin{abstract}
ÖZET
Bu çalışmanın amacı; ağır killi aluviyal bir toprak profilinde yüzey altı boru drenajının etkinliğini test etmek, buna bağlı yüzey altı drenaj akışlarının toprak su potansiyeli aralıklarını ve taban suyu seviyelerini tespit ederek mevsimsel yağışlara bağlı dağılımını ortaya çıkarmaktır. Toprak su potansiyelini, drenaj akışlarını, taban suyu seviyelerini ve iklim parametrelerini gözlemlemek üzere Gardner tarla tipi irrometre/tansiyometreleri, meteoroloji istasyonu, dijital su sayaçları, otomatik nem kaydediciler ve piyezometreler Amik Ovası, Üçgedik mevkisinde Tarla 49 araştırma istasyonunda ağır killi aluviyal topraklar üzerine kurulmuştur. Tansiyometrik nem potansiyeli 0-30 cm derinlikte 3.8$16 \mathrm{kPa}, 30-60 \mathrm{~cm}$ derinlikte12-16 kPa ve 60-90 cm derinlikte 15-20 kPa arasında değişmiştir. Drenaj akışları (3873 L ve $1556 \mathrm{~L}$ ) yağışlardan 5-7 gün sonra yukarıda verilen nem potansiyel sınırları arasında oluşmaya devam etmiştir. Drenaj çıkış ağzının boşaltım kanalına paralel piyezometre bataryası (7-8-9) su seviyeleri yüksekten düşük seviyelere değişirken sırasıyla 54 cm'den 132 cm'ye, 77 cm'den 122 cm'ye ve 117 cm'den 152 cm'ye kadar düşmüştür. Dren lateralleri arasında yerleşik piyezometreler (4-5-6) dren derinliği olan $100 \mathrm{~cm}$ seviyesini geçmemiştir. Bunun tersine drenaj çıkış ağzına en uzak piyezometre bataryası (1-2-3) en yüksek su seviyelerini kaydetmiş ve sırasıyla 13396, 103-73 ve 119-77 cm değerine yükselmiştir. Yağış miktarı ve infiltrasyon $45 \mathrm{~cm}$ toprak derinliğine kadar sınırlı etkide bulunmuş ancak genellikle dren borularına ulaşamamıştır. Yüzey toprak katmanına gömülen tansiyometreler yağışlara en erken tepki verirken daha derinlere gömülen tansiyometreler 4-6 günde tepki vermişler, ancak taban suyu seviyesindeki dalgalanmalar $90 \mathrm{~cm}$ derinliğe gömülen tansiyometreler üzerinde yağışlardan daha etkili olduğu görülmüştür. Piyezometrelerin su seviyeleri bahar dönemi ve yaz başlangıcında $44-157 \mathrm{~cm}$ arasında değişmiş ve erken bahar döneminde de 0-44 cm arasında dalgalanmaya en az 24 gün devam etmiştir. Sonuç olarak, yüzey altı boru drenaj sistemi etkin çalışmasına rağmen suyun yüzeydeki akışı nedeniyle tarlada göllenmeye devam etmiştir. Elde edilen sonuçlar kombine drenaj sisteminin çalışma alanında drenaj zararını azaltmada etkin olabileceğini göstermiştir.
\end{abstract}

Anahtar Kelimeler: Tansiyometre; Drenaj; Yağış; Taban suyu seviyesi; Killi toprak

\section{The Distirbution of Tensiometric Moisture Potential in Relation to Seasonal Rainfalls for a Tile Drained Clayey Soil}

\author{
ARTICLE INFO \\ Research Article \\ Corresponding Author: Rifat AKIŞ, E-mail: akiskoy@gmail.com, Tel: +90 (326) 2455836 \\ Received: 26 January 2013, Received in Revised Form: 24 March 2014, Accepted: 1 April 2014
}




\begin{abstract}
The objective of this study was to investigate the effectiveness of tile drainage system, tile flow rates in relation to soil matric potential ranges and water table levels based on seasonal rainfalls in a heavy clayey alluvial soil profile. In order to observe water potential, drain flows, water table levels, climatic parameters, Gardner's field type irrometers/ tensiometers, a weather station, digital water flow meters, automated moisture probes, and piezometers were established in Tarla 49 station with heavy clay alluvial soils, Üçgedik, the Amik Plain. Tensiometric moisture potentials in the 0-30, 30-60, and 60-90 cm layers varied from 3.8 to 16 , from 12 to 16 , and from 15 to $20 \mathrm{kPa}$, respectively. Drain flows of 3873 and 155611 occurred according to the given moisture potentials 5 to 7 days after rainfalls. Water levels in piezometer battery (7-8-9), parallel to the flow channel of outlet, varied from high to low; 54-132, 72-122, and 117-152 $\mathrm{cm}$, respectively. The piezometer battery (4-5-6), installed between laterals, registered very rarely high water table levels greater than drain depth of $100 \mathrm{~cm}$. On the other hand, the piezometers $(1-2-3)$ farthest from the drain outlet registered the highest water table levels varying from 133 to 96,103 to 73 , and 119 to $77 \mathrm{~cm}$, respectively. The rains and infiltration were effective in $0-45 \mathrm{~cm}$ depth. The tensiometers in deeper depths responded to the rains between 4 and 6 days. Water table fluctuations were more effective than rains on the $90 \mathrm{~cm}$ depth tensiometers. Piezometer heads ranged from 44 to $157 \mathrm{~cm}$ in the spring and early summer and 0 to $44 \mathrm{~cm}$ for at least 24 days in the early spring. In conclusion, tile drainage system was operable effectively while runoff flow was ponding in the field. Therefore, a combined drainage system could remedy drainage hazard in the study area.
\end{abstract}

Keywords: Tensiometer; Tile drainage; Rainfall; Groundwater level; Clay soil

(C) Ankara Üniversitesi Ziraat Fakültesi

\section{Giriş}

Tansiyometreler toprak tanelerinin toprak suyunu çekme kuvvetinin bir göstergesi olan toprak su potansiyelini (toprağın matrik potansiyelini) ölçmede kullanılırlar (Young \& Sisson 2002). Tansiyometrenin okuduğu toprak matrik potansiyel değeri bir toprağa verilecek suyun miktarını değişik basınç birimleri cinsinden verirken, bu okunan değerin karşıllk geldiği toprak nem miktarı (hacimsel ya da gravimetrik) aynı toprağın nem karakteristik eğrisinden hesaplanabilir. Aynı zamanda tansiyometrenin okuduğu toprak su potansiyeli değeri toprak nem miktarı hakkında da bilgi verdiği için toprağın sulama zamanlaması hakkında karar vermede de kullanılabilir. Tansiyometrenin gömüldüğü derinlik toprağın hangi derinliğinin suyla doyurulması gerektiğini gösterir (Dane et al 2006).

Topraktan drene edilmesi gereken su miktarı da tansiyometre okumaları ve nem karakteristik eğrilerinin birlikte kullanımıyla belirlenebilir. Örneğin suyla doygun haldeki bir toprak tarla kapasitesi değeri civarındaki bir su basınç potansiyeline kadar drene edilebilir. Dane et al (2006) bir topraktaki nem potansiyel dağılımını sonsuz su stresi, orta derece su stresi $(-60 \mathrm{kPa})$ ve sifir su stresi $(-30 \mathrm{kPa})$ değerleriyle saturasyon derecesine göre sınıflamışlardır. Buna göre, Wery (2005) toprak köklenme derinliğindeki su potansiyelinin tansiyometrik değerlerini bitkinin ihtiyacı olan ve karşılanması gereken nem açığı (eksikliği) olarak ifade ederken kök derinliğinden daha derinlere sızan suyu belirlemek için gömülen tansiyometrelerde okunan değerler toprak drenaj suyunun kontrolü amaçlı değerlendirilmiştir (Cuny et al 1998).

Birden fazla tansiyometre değişik toprak profil derinliklerine gömüldüklerinde suyun toprak içerisindeki akışı, kapillar yükselme, bitki su tüketimi, buharlaşma ve yağışın toprak içinde akan miktarı hakkında bilgi toplamak mümkün olabilir. Tansiyometreler suyun toprak içindeki hareketini gözlemlemede çok sıklıkla kullanıldıklarından toprak drenajının dolaylı değerlendirilmesinde önemli ekipmanlardır (Gaudin \& Rapanoelina 2003). Tansiyometreler 0-85 kPa (Richards 1949; Campbell 1988) aralığında toprak suyunun potansiyelini ölçebilme yeteneğindedirler. Bu durumda hava giriş değeri drenajın başlangıcı olarak kabul edilirse her bir derinlik için drenaj suyunun kontrolü ve yönetimi 
yapılabilir. Ancak bu güne kadar drenaj prensiplerine göre drenaj sistem planlaması yapılmış topraklarda toprak nem potansiyelinin dağılımı yeterince araştırılmadığı için (Rahardjio et al 2003) bu konuda çalışmalara ihtiyaç duyulmaktadır.

$\mathrm{Bu}$ çalışmanın yapıldığı Amik Ovası toprakları her yıl Haziran ayının ortalarından Ekim ayının başlangıcına kadar geçen sürede kurak bir dönem geçirirken yılın geriye kalan süresinde çok şiddetli ve devamlı sel baskını riski altındadır. Kısa sureli ve yükssek şiddete sahip yağışlar çok sıklıkla oluşmalarına rağmen uzun sureli, düşük şiddetli ve devamlı yağışlar kaçınılmaz bir şekilde sele dönüşmektedirler (basılmamış iki ardışık yıl iklim verileri, R. Akış). $\mathrm{Bu}$ nedenle Amik Ovasında I. ürün ekim döneminde sulama suyu kaynağı mevsimsel yă̆ışlardan sağlanırken, II. ürün ekimlerde sulama yeraltı su kuyularından ve Tahtaköprü Barajından sağlanan suyla yapılmaktadır. Kısa süreli ve yüksek şiddetli yağışlar toprak suyunda yeterli miktarda matrik potansiyel oluştururken, yüksek şiddette ve uzun süreli yağışlar toprağı yüzeye kadar doygunlaştırıp toprağın matrik potansiyelini yenerek suyun yüzey akışa ve derine sızmasina sebep olurlar ( $L$ in et al 1996). Toprak matrik potansiyelinin sıfir enerji düzeyine ulaştığı andan itibaren toprak kök derinliğindeki fazla suyun topraktan uzaklaştırılması için lateral drenlerin toprak profiline yerleştirilmesi gereklidir. Lateral dren boruları aracılığıyla topraktaki fazla su istenen kök derinliğine düşünceye kadar drene edilirken toprak matrik potansiyelde negatif olarak artar. Başka bir değişle toprağın matrik potansiyeli lateral drenler tarafindan istenen limit değerlerde kontrol edilmeye çalışılır (Rahardjio et al 2003; Martin et al 1994).

Bir dren borusundan su akışı meydana gelirken toprak nem potansiyelinin hangi değerler arasında dağılım gösterdiği o toprakta drenaj sisteminin etkinliği için iyi bir gösterge olmasının yanında toprak suyunun kontrolünde bir vasita olarak kullanılabilir. $\mathrm{Bu}$ çalışmanın amacı ağır killi aluviyal toprak profilinde yüzey altı boru drenajının etkinliğini test etmek ve yüzey altı drenaj akışlarının buna bağlı toprak su potansiyeli aralıklarını ve taban suyu seviyelerini tespit ederek mevsimsel yağışlara bağlı dağılımını ortaya çıkarmaktır.

\section{Materyal ve Yöntem}

\section{1. Çalışma alanı}

Bu çalışma Araştırma ve Uygulama çiftliklerindeki beş hektarlık bir alanda Mayıs 2010 ve Aralık 2011 yıllarında iki yıllık sürede yapılmıştır. Çalışma alanı ağır killi bir bünyeye sahip olup düz ve düze yakın bir yüzey rölyefine sahiptir. Bu araştırma alanında genellikle bağcılık, Trabzon hurması ve zeytin tarımı uygulanmaktadır. Toprak profili A ve Bt (argillic) horizonlarından oluşmakta ve bazı noktalarda 120 $\mathrm{cm}$ derinliğe ulaşmaktadır. Çalışma alanı toprakları genetik olarak yüzeyi atmosfer basıncına açık sıkışmamış akifer yapıları içinde yer aldıklarından taban suyu seviyesi I. ekimin yapılabilmesini çoğunlukla geciktirmektedir. Toplam yağış ve evapotransprasyon $1141 \mathrm{~mm}$ ve $1278 \mathrm{~mm}$ olarak kaydedilmiştir (DSİ 1962). Yağışlar \% 35 kış, \% 29 bahar, \% 12 yaz ve \% 24 sonbaharda oluşmaktadır. Bütün ova boyunca taban suyu 10 ile $300 \mathrm{~cm}$ derinlikler arasında değişmektedir (DSİ 1962). Sulama suyunun tuzluluk sinıfları $\mathrm{C}_{4} \mathrm{~S}_{1}, \mathrm{C}_{4} \mathrm{~S}_{2}$ ve $\mathrm{C}_{5} \mathrm{~S}_{1}$ olarak belirlenmiştir (USSLS 1954). Çalışma boyunca iki yıllık ortalama hava sicaklığg $18.1{ }^{\circ} \mathrm{C}$ olarak kaydedilmiştir.

\subsection{Drenaj sistemi ve geometrisi}

Çalışma alanında $70 \mathrm{~mm}$ çapında 4 lateral dren ve $100 \mathrm{~mm}$ çapında bir ana dren borusu mevcut olup 3 havalandırma kapağı ve bunların $75 \mathrm{~cm}$ çapında ve $150 \mathrm{~cm}$ derinliğinde beton havalandırma yapıları mevcuttur. Dren aralıkları $15 \mathrm{~m}$ ve dren derinlikleri $1.0 \mathrm{~m}$ olarak projelenmiştir. Bütün lateraller tamamen bağımsız paralel hat olarak araziye yerleştirilmiş ve direk olarak havalandırma varilinin içine açılmaktadırlar. Daha sonra buradan daha büyük çaptaki ana dren borusu vasıtasıyla dren akışları araziyi terk etmektedirler. Bütün drenaj sistem boruları aynı özellikteki silindirik tırtıllı sırt delikli PVC plastik borulardan oluşmaktadır. Dren çıkış ağzı özel bir beton koruma yapısı içine alınmış ve çıkış ağzının açık dren kanalının tabanına olan yüksekliği yaklaşık $26 \mathrm{~cm}$ olarak ölçülmüştür. Bu drenaj kanalı zaman zaman siltlendiğinden çıkış ağzının kanal tabanından olan yüksekliği zaman içinde değişebilir. Drenaj akışları dren borularının havalandırma 
yapılarına açıldığg yerlerde ve ana dren borusunun araziyi terk ettiği çıkış ağzında borulara bağlanmış dört su sayacıyla ölçülmüştür. Su sayaçları $100 \mathrm{ml}$ hassasiyette olup beş dijital basamağa sahiptir. $\mathrm{Bu}$ su sayaçları ülkemizde İzmir'de ticari bir marka olan Baylan Firması'ndan temin edilmişlerdir. Bu sayaçların 1 L suyun sayaçtan geçtiğini göstermesi için en sağdaki basamaktan en soldaki basamağa doğru makaraların sırasıyla $10^{3}, 10^{2}, 10$ ve 1 defa dönmeleri gerekmektedir. Okunan 1000 L değeri sayacın ana gövdesi üzerinde bulunan beş haneli dijital göstergenin birler basamağı olarak ana gösterge panelinde yerini alır. Sayaçtan her bir litre su geçtiğinde ana panel değerleri bu miktarı bir önceki değere ekleyerek dijital olarak kaydetmektedir.

\subsection{Toprak su potansiyeli}

Bu çalışmada lateral drenlerin toprak nem potansiyeli üzerine olan etkisi her yağış olayından sonra incelenmiştir. Dokuz tansiyometre lateral drenler arasına ve dokuz tansiyometre de drenler üzerine 90 , 60 ve $30 \mathrm{~cm}$ siralamasiyla dren hatlarından $1 \mathrm{~m}$ ve tansiyometreler arası $1 \mathrm{~m}$ olacak şekilde derinliklere yerleştirilmiş̧ir. Tansiyometreler $120 \mathrm{~cm}$ boyunda 5 cm çapında bir Edelman burgu (Eijkelkamp, NL) yardımıyla arazide açılmış kuyulara yerleştirilmiştir. Tansiyometrelerin toprakla teması poroz kapların havasının giderilmesi ve poroz kapların toprak profiline yerleştirilmeden önce suyla doyurulması ve $0.1 \mathrm{MPa}$ basınçla sızmaya karşı testleri Cassel \& Klute (1986)'e göre yapılmıştır. Tansiyometreler genellikle $60 \mathrm{kPa}$ değerini gösterdiklerinde su eklenerek yeniden havaları giderilmiştir. Tansiyometreler Soil Moisture Company, USA tipi manometreli Gardner irrometre/tansiyometre sinifi olarak bilinmektedir.

Toplam 18 tansiyometre kullanılarak drene edilen koşullarda toprağın değişik derinliklerindeki nem potansiyelleri ölçülmüş ve çalışma alanında sürekli kurulu bulunan meteoroloji istasyonu (Weatherlink Vantage Pro 2, Davis Instrument) $30 \mathrm{~cm}$ ve $60 \mathrm{~cm}$ derinliğe gömülmüş toprak nem propları otomatik olarak her yarım saatte bir alınan toprak nem potansiyel değerlerini kaydetmiştir. Daha sonra tansiyometre değerleriyle propların nem potansiyeli değerleri karşılaş̧ırılmıştır.

\subsection{Piyezometre su seviyelerinin ölçümü}

Tansiyometrelerin yerleştirilmeleri sırasında kullanılan ayarlı Edelman burguları kullanılarak yüzeyden $2.3 \mathrm{~m}$ derinliğe ulaşılıncaya kadar burgu kuyuları açılmıştır. Bu kuyulara $7 \mathrm{~cm}$ kalınlığında 2-4 mm elekten geçirilmiş kum malzemesi doldurulmuştur. $\mathrm{Bu}$ işlemin amacı toprak suyu ince bünyeli bir katmandan kaba bünyeli bir katmana geçerken gradiyent (hidrolik eğim) farkı oluşturarak suyun piyezometre kuyularına akışını kolaylaştırmaktır. Daha sonra dokuz adet piyezometre burgu kuyusuna yerleştirilerek çamur çorbasıyla etrafı doldurulmuş ve sızdırmazlık sağlanmıştır. Piyezometre okumaları, su tablasına temas ettiğinde lambası yanan 1şıklı ve ses sistemine sahip dereceli iletken şeritli bir makara yardımıyla yapılmıştır. Pizeometrelerin toprak üstünde kalan yükseklikleri arazi yüzeyine göre düzeltildikten sonra taban suyu seviyeleri yüzeyden taban suyu tablasına olan derinlik olarak ölçülmüştür.

\section{5. İklim parametrelerinin ölçümü}

Çalışma alanında Vantage Pro 2 (Davis Instrument, USA) meteoroloji istasyonu kurulmuş ve iki yıl boyunca anlık olarak iklim parametreleri belirlenmiştir. Bu çalışmanın amacına ulaşmak için yağış miktarı, şiddeti ve evapotransprasyon (ET) değerleri bu istasyondan alınarak kullanılmıştır. İstasyona bağlı bir GPRS yardımıyla istasyondaki veriler uzaktan bir telemetre aracılığıyla bilgisayara yüklenmiş ve telemetrenin hassasiyet ayarları yapılmıştır. İklim parametreleri istenilen zaman aralıklarında toplanabilecekken, geleneksel iklim verileri her yarım saatte bir alındığından iklim istasyonu her yarım saatte bir 9 sensörden aldı iklim ve toprak verilerini kaydetmek (sicaklık, yaprak alan indeksi, yağışın şiddeti, yağışın yüksekliği, evapotransprasyon, solar radyasyon, solar enerji, barometrik basınç, rüzgar hızı, rüzgar yönü, toprak nemi, toprak sicaklığı, havanın yoğunluğu, çiğlenme noktası, bağıl nem ve bunlara bağlı indeks değerlerle birlikte toplam $40 \mathrm{iklim}$ parametresi) üzere ayarlanmıştır. İklim istasyonu Akdeniz'in deniz suyu yüzeyinden $71 \mathrm{~m}$ yüksekte bulunmaktadır. Bu değer yüksek çözünürlüğe sahip 
bir GPS aleti tarafindan en az 3 uydudan alınan koordinatlarla yapılan konum belirleme sürecine göre arazide istasyon firmasının uzmanları tarafindan hesaplanmıştır. Buna göre, Antakya merkez ilçe rakımının $85 \mathrm{~m}$ olduğu göz önünde tutulursa, çalışmanın yapıldığı deneme alanı eski kurutulmuş Amik Göl’ü alanı içerisinde kalmaktadır.

\section{Bulgular ve Tartışma}

\subsection{Iklim verileri}

Çalışma alanında kurulu bulunan meteoroloji istasyonu kayıtlarından günlük yağış, ET ve toprak nem potansiyel değerleri alınmıştır (Şekil 1). Bu iklim istasyonu verilerine göre 2011 yllının OcakNisan aralığında yağış miktarının evapotransprasyon değerlerinden fazla olduğu görülmektedir. Mayıs ayından itibaren aylık ET değerleri yıl sonuna kadar kaydedilmiş olan aylık yağış değerlerinden daha büyüktür. Bunun sonucu olarak toprakta nem açığı oluşmuştur. Mayıs ayından sonra toprak profilinde toprak su potansiyelinin azalışı (negatif basınçta $(\mathrm{kPa})$ artış) toprak nem potansiyel eğrisinden anlaşılmaktadır. 13-15 Haziran arasındaki 21 mm'lik yağıştan dolayı toprak nem potansiyeli oldukça hızlı artış göstermiş toprağın matrik potansiyeli (gözenek suyunun basınc1) -166 kPa değerinden $-4 \mathrm{kPa}$ değerine düşmüştür. Matrik potansiyelin bu şekilde azalması toprakta nem içeriğinin arttığ 1 ve suyun toprak tarafindan tutulması için daha az enerji harcandığını göstermektedir. Başka bir değişle toprak profilinde drene edilebilecek su miktarı artmaya başlamıştır. Ancak $-4 \mathrm{kPa}$ değerine karşın herhangi bir dren akışı oluşmamıştır. 15 Hazirandan itibaren toprak suyunun potansiyeli ya da topraktaki nem miktarı Ekim ayına kadar sürekli bir şekilde azalmaya devam etmiştir. Ekim ve Kasım aylarında sırasıyla 55 ve $32 \mathrm{~mm}$ yağış yağmışsa da ET (sırasıyla, $62 \mathrm{~mm}$ ve $44 \mathrm{~mm}$ ) daha fazla gerçekleşmiştir. Ancak Ekim ve Kasım ayları 2011 için kurak geçmiştir. Toprak nem ve sıcaklık propları yıllık bakıma alındığından Eylül-Aralık, 2011 arasında toprak nem potansiyeli ve sıcaklığ otomatik proplarla ölçülememiştir (Şekil 1).

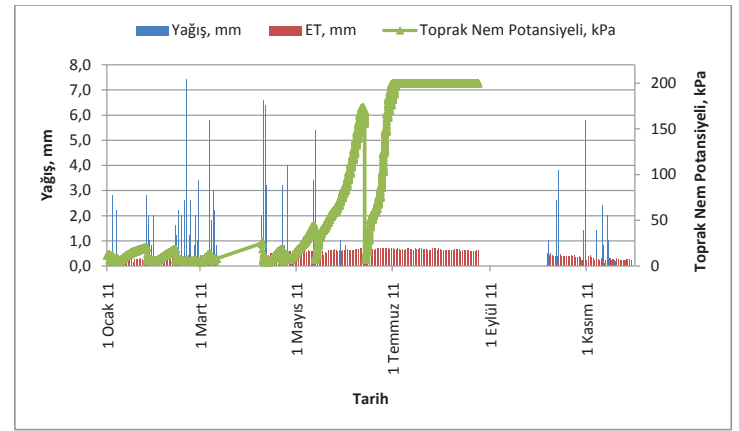

Şekil 1- Çalışma alanında kaydedilen günlük meteorolojik veriler (yağış $(\mathrm{mm})$, ET (mm) ve toprak nem potansiyeli (kPa))

Figure 1-Daily meteorological data records from the experimental site (rainfall ( $\mathrm{mm})$, ET ( $\mathrm{mm})$, and soil moisture potential $(\mathrm{kPa})$

\subsection{Yă̆ış ve yüzey akışlar}

Çizelge 1'de denemenin yapıldı̆̆ 1 dönemde arazi şartlarında oluşan günlük yağışlar, ET değerleri ve ortalama gözenek suyu basınç değerleri (GSB) karşılaştırma yapabilmek için verilmiştir. $\mathrm{Bu}$ karşılaştırmalar suyun toprak içindeki hidrolik eğimi dikkate alınarak yapılmıştır. Hidrolik eğim, Darcy denklemi yardımıyla hesaplanabilir.

$$
q=-K \frac{\partial H}{\partial z}
$$

$\mathrm{Bu}$ denklemde; $\mathrm{q}$, akış yoğunluğu $\left(\mathrm{m}^{3} \mathrm{~m}^{-2} \mathrm{~s}^{-1}\right)$; $\mathrm{K}$, hidrolik iletkenlik değeri $\left(\mathrm{m} \mathrm{s}^{-1}\right) ; \mathrm{H}$, hidrolik yük (m); z, profil derinliği (m) değerlerini göstermekte olup toprak profilinde yukarı yönlüyse pozitif, aşağı yönlüyse negatif değerler alır. Toprak profilinde etkili olan hava basıncının atmosfer basıncına eşit olduğu varsayıldığında hidrolik yük aşağıdaki gibi gösterilir.

$$
H=h_{m}+z
$$

Toprak yüzeyi referans noktası olarak alınırsa, $\mathrm{z}$ değerleri $-30 \mathrm{~cm},-60 \mathrm{~cm},-90 \mathrm{~cm}$ ve $-100 \mathrm{~cm}$ olur. Toprak matrik potansiyeli $\left(\mathrm{h}_{\mathrm{m}}\right)$ ve $\mathrm{z}$ değerlerinin bilinmesiyle toprak suyunun akış yönü belirlenebilir. Hidrolik eğimlerin pozitif olması taban suyunun profilde yukarıdan aşağı doğru hareket ettiğini ve negatif olması da suyun toprak profilinde alttan 
yukarı doğru aktığını göstermektedir. Çizelge 1'e göre, toprak nem potansiyeli 2-8 Ocak arasında -6$(-12) \mathrm{cm}$ arasında değişirken hidrolik eğim 1.007 ile -1.2 arasında değişmiş ve toplam olarak $7.6 \mathrm{~cm}$ hidrolik yük farkı oluşmuştur. 26-31 Ocak arasında toprak nem potansiyeli $-9.6-(-5.7) \mathrm{cm}$ arasinda değişirken hidrolik eğim -1.01 ile -1.087 arasında değişerek hep negatif kalmıştır. Bu dönemde toplam olarak $4.6 \mathrm{~cm}$ hidrolik yük farkı oluşmuş ve taban suyu yukarı hareket etmiştir. 13-14 Şubat aralığında toprak nem potansiyeli -17.8 ile $-6.8 \mathrm{~cm}$ arasında değişirken, hidrolik eğim negatif değer alarak -1.03 ile -1.37 olmuş ve toplamda $11 \mathrm{~cm}$ hidrolik yük farkı oluşmuştur. Sonuç olarak taban suyu toprak yüzeyine doğru hareket etmiştir. Bunların tersine bir durum olarak 6-13 Şubat arasında toprak nem potansiyeli -12 ile $-17.8 \mathrm{~cm}$ arasında değişmiş, buna bağlı olarak hidrolik eğim -1.03 ile -1.19 arasında değişmiş toplamda hidrolik yük $5.8 \mathrm{~cm}$ değişmiş ve toprak profilinde su hareketi alttan yukarı doğru gerçekleşmiştir. Sonuç olarak Ocak sonundan itibaren eğim negatif olduğu için toprak profilinde su yukarı doğru hareket etmiştir. Buna bağlı olarak oluşan yüzey akışlar 2-8 Ocak tarihleri arasinda 3, 26-31 Ocak tarihleri arsinda 5 ve 1314 Şubat tarihleri arasında 1 olmak üzere toplam 9 defa oluşmuştur. 14 Şubat tarihinden sonra yağış ve yüzey akışlar ( 8 tane) artmış ancak yüzey akışlar toplanamamıştır.

$\mathrm{Bu}$ dönemde drenlere bağlı sayaçlar ve havalandırma yapıları su altında kaldıklarından, ancak seller çekildikten sonra toplam drenaj akışı kaydedilmiştir. Çalışma alanı toprağının bir günde geçirebileceği su miktarı $33.6 \mathrm{~mm}\left(\mathrm{Ks}=0.14 \mathrm{~cm} \mathrm{~h}^{-1}\right)$ ölçüldüğünden, oluşan yüzey akışlar 29-33.9 mm arasında değişmektedir. Deneme alanında Aralık 2010 ve Ocak - Şubat, 2011 aylarında sirasıyla $11.87,38.8$ ve $38.26 \mathrm{~mm}$ toplam evapotransprasyon oluşmasına rağmen, aynı dönemlerde toplam yağışlar sırasıyla $0.2,89.2$ ve $119.4 \mathrm{~mm}$ olarak gerçekleşmiştir (Çizelge 1).

Çizelge 1'deki toprak nem probunun gösterdiği değerler her ne kadar tam olarak suyla doygunluk şartlarını göstermese de toprak nem potansiyeli doygunluk derecesine çok yakındır. Bradley et al (2010) tansiyometrelerin bireysel yağışlara çok çabuk tepki verirken toprak profilinde suyla doygunluk şartlarına yaklaşıldıkça toprak suyunun matrik potansiyelinde dalgalanmalar oluşması nedeniyle tam sıfır $\mathrm{kPa}$ basınç değerini göstermediklerini ve bu nedenle $-18 \mathrm{~cm}$ değerini (-1.8 kPa) sıklıkla okuduklarını bildirmektedirler. Kış ve bahar aylarında tansiyometrelerin yağışlara verdikleri tepkilerin değişik olmasını toprak yüzeyinin mikro rölyefinin engebeli olmas1 (heterojen) ve suyun hareket deseninin yersel değişkenliğiyle açıklamaktadırlar.

Çizelge 1- Deneme alanındaki 0-30 $\mathrm{cm}$ toprak katmanı için toprak nem probu günlük ortalama gözenek suyu basınçları, yağışlar ve ET değerleri

Table 1-Daily averages of pore water pressures of soil moisture probe, rainfall, and ET values for $0-30 \mathrm{~cm}$ soil layer in the experimental site

\begin{tabular}{rrrr}
\hline \multicolumn{1}{c}{ Tarih } & $\begin{array}{r}\text { Yă̆ı̧ } \\
(\mathrm{mm})\end{array}$ & ET $(\mathrm{mm})$ & $\begin{array}{r}\text { Ortalama } \\
\left(\mathrm{cmH}_{2} \mathrm{O}\right)\end{array}$ \\
\hline $12 / 28 / 2010$ & 0.2 & 1.13 & -8.7 \\
$1 / 2 / 2011$ & 0.8 & 0.57 & -12.0 \\
$1 / 3 / 2011$ & 0.2 & 0.51 & -6.0 \\
$1 / 4 / 2011$ & 11.2 & 0.28 & -6.8 \\
$1 / 7 / 2011$ & 19.4 & 1.45 & -7.0 \\
$1 / 8 / 2011$ & 0.2 & 1.59 & -6.0 \\
$1 / 26 / 2011$ & 17.4 & 0.21 & -9.6 \\
$1 / 27 / 2011$ & 19.2 & 0.8 & -7.0 \\
$1 / 28 / 2011$ & 4.6 & 1.61 & -6.3 \\
$1 / 29 / 2011$ & 5.6 & 2.29 & -6.0 \\
$1 / 30 / 2011$ & 10.4 & 2.29 & -5.7 \\
$1 / 31 / 2011$ & 0.2 & 1.74 & -5.0 \\
$2 / 6 / 2011$ & 0.2 & 2.28 & -12.0 \\
$2 / 13 / 2011$ & 5.6 & 0.33 & -17.8 \\
$2 / 14 / 2011$ & 5.4 & 1.01 & -6.8 \\
$2 / 15 / 2011$ & 15.0 & 1.28 & -7.0 \\
$2 / 16 / 2011$ & 1.2 & 1.55 & -6.7 \\
$2 / 17 / 2011$ & 7.4 & 0.48 & -6.0 \\
$2 / 18 / 2011$ & 1.6 & 2.46 & -5.8 \\
$2 / 19 / 2011$ & 4.4 & 1.25 & -5.8 \\
$2 / 20 / 2011$ & 33.8 & 1.79 & -5.5 \\
$2 / 21 / 2011$ & 0.4 & 2.06 & -6.0 \\
$2 / 22 / 2011$ & 3.8 & 1.81 & -5.5 \\
$2 / 23 / 2011$ & 3.0 & 0.75 & -5.6 \\
$2 / 24 / 2011$ & 0.2 & 1.36 & -5.0 \\
$2 / 25 / 2011$ & 2.4 & 1.11 & -6.1 \\
$2 / 26 / 2011$ & 13.4 & & -6.0 \\
$2 / 27 / 2011$ & 3.6 & & -5.6 \\
$2 / 28 / 2011$ & 18.0 & & \\
\hline Toplam & 208.8 & 88.93 & \\
\hline & & & \\
\hline & & \\
\hline
\end{tabular}




\subsection{Yüzey toprak derinliğinin $(0-30 \mathrm{~cm}) \mathrm{nem}$ potansiyeli}

Toprak nem potansiyelindeki değişimler iklim şartlarına ve toprakta suyun hareketine bağlı olarak $30 \mathrm{~cm}$ derinliğe sahip yüzey toprağında en net şekilde görülmektedir (Şekil 2). Genel olarak toprak gözenek su potansiyeli $-38 \mathrm{~cm}$ su sütunu $(-3.8 \mathrm{kPa})$ ile $-162 \mathrm{~cm}$ su sütünu $(-16.2 \mathrm{kPa})$ aralığında değişmiştir. Brooks ve Corey (1964) e göre killi bir toprakta makro gözeneklerden drenajın başlayabilmesi için havanın bu gözeneklere giriş değeri $60 \mathrm{~cm}$ negatif basınç değeri kullanılabilir. 4-5 Ocak aralığında yüzey toprak katmanı drene olmaya başlamıştır. 7-13 Ocak aralığında hem yüzey akış hemde suyla doygunluk şartları birlikte gerçekleşmiştir. Yağışın zamanlaması ve miktarına bağlı olarak toprak nem potansiyeli de artmaya başlamıştır (2-12 Ocak arası). 16-17 Ocak ve 21-22 Ocak tarihlerinde metoroloji istasyonu hiçbir yağış kaydetmemesine rağmen tansiyometrelerle okunan toprak nem potansiyelinde küçük de olsa artışlar görülmektedir. Bu durum bu mevsimde 2-3 günlük aşırı çiğ oluşumu ve buharlaşmanın azalmasıyla açıklanabilir (Şekil 2). Bunun yanında, toprak dren derinliğinde taban suyu tablasının yükselişide yüzey toprak katmanında toprak nem potansiyelinin artışına neden olmuştur. Çünkü 18-25 Ocak arasındaki gözenek suyu basıncı davranışları 60 ve $90 \mathrm{~cm}$ derinliklerdekiyle benzerdir.

Daha sonra 30 Ocak - 13 Subat arasında yeterli miktarda yağış yağmadığından toprak nem potansiyeli azalmıştır ve daha negatif değerler almıştır.15 Şubat 2011' den itibaren Amik Ovası şiddetli ve devamlı yağan yağışlarla sellere maruz kalmış olduğundan hiçbir tansiyometre okuması yapılmamıştır. Genel olarak incelendiğinde sabah saatlerinde okunan tansiyometre değerleri akşam saatlerinde okunan değerlerden göreceli olarak daha az negatiftir. Yani toprak akşama doğru daha kurumuştur. Toprak nem potansiyeli en çok yüzey toprak katmanında değişkenlik göstermiştir. Yüzey toprak nem potansiyeliyle ilgili benzer sonuçlar literatürde bildirilmektedir (Gaudin \& Rapanoelina 2003; Wang et al 2007; Bradley et al 2010).

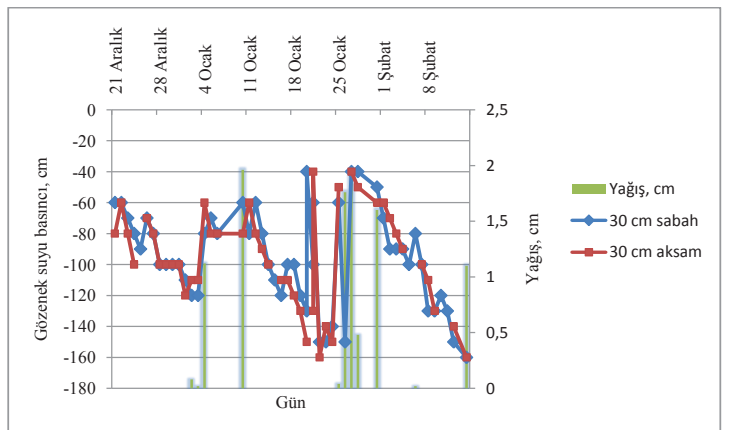

Şekil 2- Gözenek suyu basıncı okumaları $(30 \mathrm{~cm}$ derinlik)

Figure 2- Pore water pressure readings for 30-cm depth

\subsection{Toprak nem potansiyeli (30-60 cm derinlik)}

Toprak neminin $60 \mathrm{~cm}$ derinlikteki dağılımı Şekil 3 te gösterilmiştir. Çok zayıfta olsa akşam okunan tansiyometre değerleri sabah okumalarına göre nisbeten daha az negatif değerler göstermektedirler. $\mathrm{Bu}$ derinlikteki toprak nem potansiyeli yüzey toprağında olduğu gibi yağışa daha hızlı tepki vermemekte ve dolayısıyla toprak nemi yağış olmasına rağmen daha geç artışa geçmektedir. Örnek verirsek, 5 Ocak tarihine kadar yağan yağışlar toprak nemini $60 \mathrm{~cm}$ derinlikte hiçbir şekilde artırmamıştır. Bunun tersine, 11 Ocak tarihine kadar yağan eklemeli yağışlar etkisini 9 gün sonra göstererek 60 $\mathrm{cm}$ derinlikteki toprak nem potansiyelini $-160 \mathrm{~cm}$ $\mathrm{H}_{2} \mathrm{O}(-16 \mathrm{kPa})$ değerinden $-120 \mathrm{~cm} \mathrm{H}_{2} \mathrm{O}(-12 \mathrm{kPa})$ değerine yükseltmiştir. 5 Ocak tarihine kadar yağan yağışların tansiyometre okumalarına yansımamış olmas1 tansiyometrelerin düzgün bir poroz kaptoprak kontağının olmayışından değil yağışların yetersizliğinden kaynaklanmaktadır. Çünkü yüzey toprak 5 Ocak tarihinde drene olmaya başlamıştır ve tansiyometreler 5 Ocak'tan sonraki yağışlara tepki göstererek toprak nem potansiyelinin $-160 \mathrm{kPa}$ dan $-120 \mathrm{kPa}$ değerine yükselmesini sağlamışlardır. $\mathrm{Bu}$ tansiyometreler aynı zamanda 15-17 Ocak, 21-22 Ocak, 3 Şubat ve 9 Şubat tarihlerinde Şekil 3’te görüldüğü gibi hava yapmışlardır. Tansiyometreye hava girişinin olduğu gerçekliği tansiyometrelerin okudukları negatif basınçlardaki ani değişimlerden anlaşılmaktadır (Rohardjo et al 2003) (Şekil 3). 


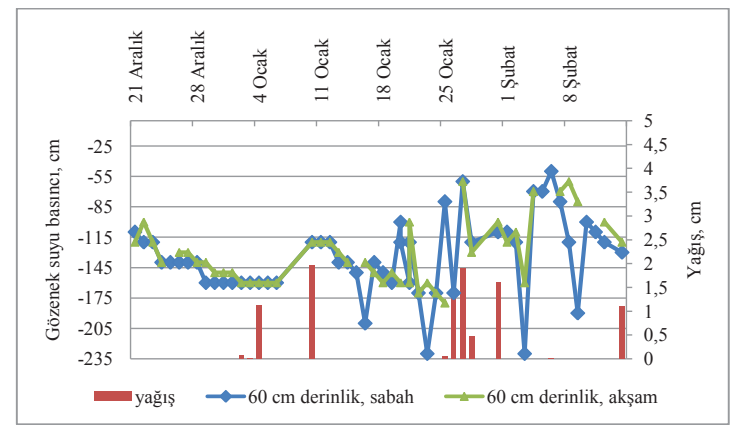

Şekil 3- Gözenek suyu basınç okumaları $(60 \mathrm{~cm}$ derinlik)

Figure 3- Pore water pressure values for 60-cm depth

\subsection{Toprak nem potansiyeli (60-90 cm derinlik)}

Deneme başlangıcından itibaren $90 \mathrm{~cm}$ derinlikteki toprakta tutulan su çok zayıf kuvvetler tarafindan tutulmuştur (-15-(-20) $\mathrm{kPa})$ ve su toprakta drene olmaya (yatayda ve düşeyde akışa) devam etmiştir. Çünkü kapillar kuvvetler tarla kapasitesi $(-33 \mathrm{kPa})$ değerinden daha zayıftır. Ancak bu potansiyeldeki sular henüz dren borularına girmemişlerdir. Sadece bu derinlik için sabah ve aksam okunan tansiyometrik nem potansiyel değerleri arasında fark $4 \mathrm{kPa}$ dan $6 \mathrm{kPa}$ değerine kadar değişmiştir. Toprak suyunun matrik basıncının bu kadar geniş aralıkta değişmesi dren derinliğinin $(100 \mathrm{~cm})$ tansiyometrenin (90 cm derinlik) okuduğu değeri çok ciddi etkilediğini göstermektedir. Bütün toprak profil derinliklerinde tansiyometrelerin okudukları nem potansiyellerinin kısa sürede olsa değişmediği 2-3 günlük dönemler kaydedilmiştir (Şekil 2, 3 ve 4). Sığ ve derin noktalara gömülmüş tansiyometrelerin okudukları toprak nem potansiyellerinin ayn olması durumu yağış ve buharlaşmanın eşit olduğu durumda toprak nem içeriğinin sabit kaldığ 1 anlamina gelmektedir (Bradley et al 2010). Toprak nem potansiyelinin bu çalışmada kışın artması ve bu artışın 5 Ocak'tan sonra sürekli olması Bradley et al (2007)'ye göre mevsimsel bir davranıştır (Şekil 4). Ocak 5'den itibaren taban suyu tablası yavaş bir şekilde yükselmeye başlamıştır. Bunun sinyallerini alttan yukarı toprak profilinde sırasıyla 60 ve $30 \mathrm{~cm}$ derinliklerdeki tansiyometre okumaları gecikmeli de olsa göstermektedir. Örneğin bu zaman aralığında (5-16 Ocak) toprak nem potansiyelini artıracak bir yağış olmamasına rağmen taban suyu çevredeki arazilerin taban suyu seviyesindeki hidrolik eğime bağlı olarak yükselmiştir. Toprak su potansiyeli $-200 \mathrm{~cm}$ den $-110 \mathrm{~cm}$ değerine yükselmiştir. Gerçek anlamda ilk dren akışları 60$90 \mathrm{~cm}$ derinlik katmanında nem potansiyeli $20 \mathrm{kPa}$ dan $10 \mathrm{kPa}$ ya yükselme aralığında ölçülmüştür. $\mathrm{Bu}$ drenaj akışlarından önceki dren kayıpları dren boruları ve hidrolik yapılarında nemlenme olarak göreceli olarak tespit edilmiştir. Bu durum yüzeyden infiltrasyonla gelen suyun ve profilde taban suyunun kapillar olarak yükselmesi durumunda bütün toprak profilinin doygun hale geldiğini göstermektedir.

Toprak profilinde 60-90 cm katmanda nem potansiyeli $10-20 \mathrm{kPa}$ arasında dağılırken dren borularına su girişi ciddi seviyededir. Yağışlara bağlı olarak 5-14 Ocak arasında iki tane drenaj akışı meydana gelmiş ve yaklaşık olarak 8 gün zayıf bir debiyle akmaya devam etmişlerdir. Birinci drenaj akış1 3873 L suyu araziden uzaklaştırırken ikinci drenaj olayı 1556 L suyu yaklaşı 3 günde araziden uzaklaştırmışıır. Bu drenaj olaylarından sonra taban suyunun yükselişine bağlı olarak dren borularında akış çok zayıf olarak devam etmiştir. Ancak yağışların 19 Ocak'tan sonra hızla sıklaşması ve yağış miktarının artması Amik Ovası'nı aşırı su yükü altında bırakmış olduğundan, dren havalandırma hidrolik yapılarında ve çıkış ağızlarındaki su sayaçları su altında kalmış ve hiçbir değer okuması yapılamamıştır.

Daha derinlere gömülmüş tansiyometrelerin $(90 \mathrm{~cm})$ yağışlara, buharlaşmaya ve bitki su tüketimine karşı verdikleri tepkilerin 30 ve $60 \mathrm{~cm}$ derinliklerdeki tansiyometrelere göre daha zayıf olduğu belirlenmiştir (Şekil 4). 15 Ocak tarihine kadar yağan yă̆ışlar dikkate alındığında, $60-90 \mathrm{~cm}$ toprak katmanı kendisinden daha yukarıda bulunan toprak katmanlarının hepsinden daha kurudur (-150 cm su sütunu yada - $15 \mathrm{kPa}$ su basinc1 potansiyeli) ve bu kuruma -22 kPa negatif basınca kadar artmaktadır. Başka bir değişle, 15 Ocak tarihine kadar yağan yağışlar henüz bu derinliğe ulaşmamıştır. Bu durum toprağın $120 \mathrm{~cm}$ derinliğe kadar ağır killi bir yapıya sahip olmasından ve hidrolik iletkenliğin düşük olmasından kaynaklanabilir. Rohardjo et al (2003), $3.2 \mathrm{~m}$ derinlikteki tansiyometrelerde gözenek suyu basıncının yağışlara ve Silber et al (2006) 60-90 
cm ve 90-120 cm derinliklerdeki tansiyometrelerin sulamaya verdiği tepkinin görünmeyecek kadar az olduğunu bildirmektedirler.

13 Ocak'tan sonra toprak nem potansiyelinde bir miktar artışlar görülmektedir. Ancak esas artışlar 18 Ocak ve 4 Şubat arasındaki şiddetli yağışlarla ortaya çıkmıştır. Bu yağışlar toprak nem potansiyelini $-17 \mathrm{kPa}$ dan $-4 \mathrm{kPa}$ değerine yükseltmiştir. Bradley et al (2010)'a göre eğer tansiyometre okumaları mutlak değer olarak çok küçük gözenek suyu basınçları okuyorsa toprakta drenaj akışları devam etmektedir. 6-14 Şubat arası kurak şartlar hüküm sürdüğünden toprak nem potansiyeli negatif olarak artmış ve $-5 \mathrm{kPa}$ dan -22 kPa değerine düşmüştür. Tansiyometrelere 9 Şubat'dan sonra hava girişi olmuştur (Şekil 4).

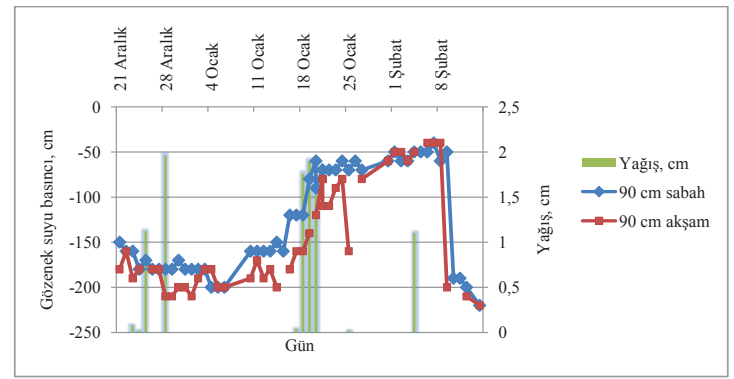

Şekil 4- Toprak gözenek su potansiyeli değerleri (90 cm derinlik)

Figure 4- Soil pore water pressure values for $90 \mathrm{~cm}$ depth

\subsection{Yağışların etkisi altında toprak profilinde tansiyometrik nem potansiyeli ve drenaj akışları}

Tanisyometrelerin yağışa ve toprak drenajına karşı okuduğu gözenek suyu basınçları Şekil 5'te gösterilmektedir. Seçilmiş yağışların dağılım ve etkileri incelendiğinde, 2-10 Ocak arası yağışlar toprağı yüzeyden $90 \mathrm{~cm}$ derinliğe kadar beslemiş ve gözeneklerin suyla dolmasını sağlamıştır. Çok zayıf da olsa taban suyunun oluşmaya başladığı, yağış-nem potansiyeli eğrilerinin $60-90 \mathrm{~cm}$ arasında kırılarak yön değiştirmelerinden anlaşılmaktadır. 6 Şubat yağışları hariç tutulursa 10 Ocak-6 Şubat arası yağışlarda toprak profilini 0-60 cm derinliğinde suyla doygunluk derecesine yaklaştırmış $(-12 \mathrm{kPa}$ dan -6 $\mathrm{kPa}$ aralığında) ve taban suyunun yükselişi artık net olarak görülmüştür. Toplam 7 yağış olayı taban suyunu 60-90 cm katmanında $-6 \mathrm{kPa}$ değeri civarında tutmuştur. Su toprakta $-60 \mathrm{~cm}$ 'den daha küçük negatif basınçlarla güçlü tutulmakta olduğundan alt katmanlara ilerleyişini sürdürmektedir. 6 Şubat yağışları direk olarak -6 kPa basınçtan daha az kuvvetle toprakta tutulduklarından direk yüzey akışlar artmış ve taban suyu artık toprak yüzeyine ulaşmış, aynı zamanda dren akışları devam etmiştir. Bütün profil derinliği tarla kapasitesinin (-33 $\mathrm{kPa})$ üzerinde bir nem potansiyeli göstermiştir (Şekil 5). Bu durum tansiyometrelerin toprak profilinde iyi derecede bir temas sağladığını göstermektedir. Çünkü taban suyu seviyesi ve yağışlardaki artışlara bağlı olarak çok yavaş bir şekilde $-2 \mathrm{kPa}$ değerine yakınsamaktadır.

Toprak profilinde ve drenaj çıkış ağzında dren akışları devam ederken tansiyometrelerde okunan toprak nem potansiyel değerleri tüm profil boyunca yaklaşı olarak -38 kPa ve -20 kPa değerleri arasında değişmiştir. Toprak drenaj akışları yağmurlardan 5-7 gün sonra oluşmaya başlamıştır. Bu da toprakta drenaj akışının düşeyde çok yavaş ve yatayda biraz daha hızlı oluştuğunu göstermektedir. Suyun bu sırada yüzey akışa geçmiş olması yatayda toprak hidrolik iletkenlik değerleri düşeydeki değerlerden daha büyük olduğu eğilimini göstermektedir.

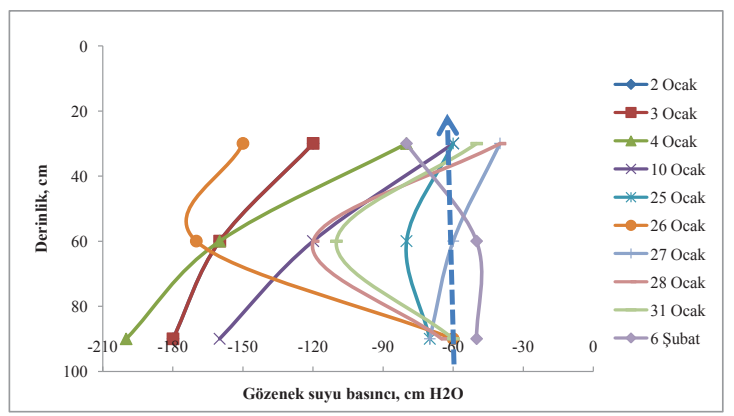

Şekil 5- Tansiyometrik potansiyel-yağış-drenaj ilişkisi

Figure 5- The relations of tensiometric potentialrainfall-and drainage

\subsection{Yağışların etkisi altında toprak nemi piyezometrik su seviyeleri ve drenaj akışlarının dağılımı}

Toprak nem probuyla otomatik olarak okunan toprak su potansiyeli ve yağışlar Şekil $6^{\circ} \mathrm{da}$ verilmektedir. Tansiyometrelerle karşılaştırıldığında toprak nem probunun yağışlara verdiği tepkiler 
tansiyometrelerden daha eşzamanlı bir durum göstermektedir. Yağışların artışına paralel olarak toprak nem potansiyeli artmaktadır. Toprak aşırı yağış yükü altında kalınca tansiyometrelerin tersine toprak nem probu toprak nem potansiyeli okumaları $-10 \mathrm{~cm}$ su kolonu $(-1 \mathrm{kPa})$ dan daha az artmaktadır. Silber et al (2007) dijital tansiyometrelerin toprak nem potansiyeline çok duyarlı olduklarını ve yağış olaylarına paralel bir değişimi kaydettiklerini bildirmektedir. Şekil 6'daki toprak nem potansiyel değerleri arasındaki kopukluklar tansiyometrelerdeki negatif basınçlardaki ani değişimlere $(-3 \mathrm{kPa}-7 \mathrm{kPa})$ göre daha düşük ve istikrarlı bir eğilim izlemektedir. Buna göre, toprak nem probu tansiyometrelere göre toprağın $30 \mathrm{~cm}$ derinliğinin çok daha sslak olduğunu göstermektedir ve toprak nem potansiyeli $-20 \mathrm{~cm}(-2$ $\mathrm{kPa})$ su sütunu yüksekliğinden daha fazla değildir. Bunun tersine tansiyometreler $30 \mathrm{~cm}$ derinlik için çok daha küçük nem potansiyel değerleri (negatif olarak çok küçük basınçlar) kaydetmişlerdir (-30 kPa). Buna rağmen toprak profili infiltrasyonla süzen su miktarı 5-7 gün içinde islanma çeperinin ilerleyişi ve taban suyunun infiltrasyondan çoğunlukla bağımsız olarak yükselmesi nedeniyle iki zit yönlü su hareketiyle tamamen doygun hale gelmiştir. 22 Aralık 2010 7 Ocak 2011 arasında yağışlar 0.2 - $19.4 \mathrm{~mm}$ arasında değişirken, eklemeli yağışlar $34 \mathrm{~mm}$ olmuştur (Çizelge 1). Aynı dönemde toprak nem potansiyeli $-12 \mathrm{~cm}(-1.2 \mathrm{kPa})$ değerinden $-5 \mathrm{~cm}(-0.5 \mathrm{kPa})$ değerine yükselmiştir (Şekil 6). 27-31 Ocak 2011 arası eklemeli yağışları $55 \mathrm{~mm}$ ye yükselirken toprak nem potansiyeli $-16 \mathrm{~cm}$ den $-5 \mathrm{~cm}$ (-1.6 kPa ile -0.5 $\mathrm{kPa})$ değerine yükselmiştir. Benzer şekilde, 6 Şubat ve sonraki yağışlar toprak nem potansiyelini $-18 \mathrm{~cm}$ den $-4 \mathrm{~cm}(-1.8 \mathrm{kPa}$ ve $-0.4 \mathrm{kPa})$ değerine yükseltmiş ve daha sonraki yağışlar direk taban suyu ve yüzey akışa katkıda bulunmuştur. Kasım 2010 - Ocak 2011 boyunca $43 \mathrm{~mm}$ ET ve $89 \mathrm{~mm}$ yağmur oluşmuştur. Şubat 2011 de bu değerler $19.74 \mathrm{~mm}$ ET ve $119.4 \mathrm{~mm}$ yağış olarak ölçülmüştür. Geriye kalan su (¿yağışEET) $1.0 \mathrm{~m}$ derinlikteki dren borularına rahatlıkla ulaşacak kadar (46 -99.3 mm) fazladır. Toprak dren derinliği suyla doygun hale gelene kadar defalarca yüzey akış olayları kaydedilmiş ve yükselen taban suyu yüzey altı drenaj sistemiyle uzaklaştırılmıştır.

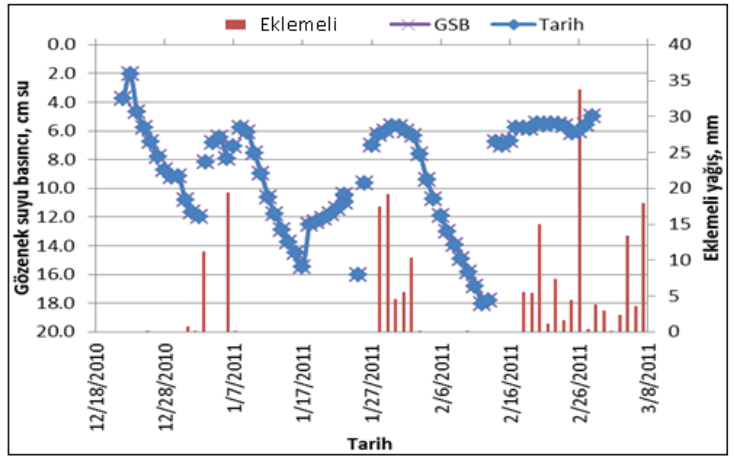

Şekil 6- Toprak nem probuyla okunan gözenek suyu basıncı ve yağış ilişkisi

Figure 6- The relationships of soil moisture probe based pore water pressure and rainfall

Drenaj sisteminin yağışlarla olan ilişkisini anlayabilmek için yeraltı suyu gözlemleri piyezometrelerle yapılmıştır. Piyezometreler 3 x 3 düzeninde 1zgara plan olarak tarlaya yerleştirilmişlerdir. Piyezometrelerin ilk üçü (12-3) ana drenaj borusundan $15 \mathrm{~m}$ uzağa bahçe kültürünün yapıldığı alana yerleştirilirken son üç tanesi (7-8-9) drenaj çıkış ağzının boşaldığı drenaj kanalına paralel diziliş göstermişlerdir. Orta sırada diziliş gösteren üç piyezometre 2 dren lateralinin arasında ortaya yerleştirilmişlerdir. 2011 yılında yağışlardan sonra sağlıklı ölçülebilen piyezometre su seviyeleri, Nisan $(12.8 \mathrm{~cm})$ - Mayis $(5.56 \mathrm{~cm})$ arasında yağan toplam yağışların eklemeli etkileri nedeniyle Haziran ayının ilk haftasına kadar azalış ve artışlar göstermiştir. Piyezometre 1 ve 2 su seviyeleri sirasiyla $134 \mathrm{~cm}$ den $96 \mathrm{~cm}$ seviyesine ve $103 \mathrm{~cm}$ den $73 \mathrm{~cm}$ seviyesine yükselirken, piyezometre 3 drenaj sorunu olan bir parsele yerleştirildiğinden $119 \mathrm{~cm}$ 'den $77 \mathrm{~cm}$ seviyesine yükselmiştir. Genel olarak piyezometre 1-2-3 dizini yüksek taban suyu seviyesi göstermektedir. Dren lateralleri arasında dizilim gösteren piyezometreler (4-5-6) diğer piyezometrelerden farklı olarak yağışların eklemeli etkisine rağmen piyezometre 4 içinde su seviyesi uzun süre $140 \mathrm{~cm}$ derinlikte kalmış ve bu seviyeyi hemen hemen hiç aşmamıştır. Piyezometre $5,115 \mathrm{~cm}$ seviyesinden 145 seviyesine 3-4 günde çok hızlı bir düşüş göstermektedir. $\mathrm{Bu}$ durum bu piyezometrenin dren lateraline ve ana drenaj toplayıcı borusuna yakınlığı nedeniyle ortaya 
çıkmış olabilir. Genel olarak piyezometre 4-5-6 serisinde su seviyeleri $100 \mathrm{~cm}$ ve üzerine çok nadir olarak çıkmıştır. Piyezometre 7-8-9 da su seviyeleri hep azalan bir seyir izleyerek sirasıyla 54 ' $\mathrm{cm}$ den $132 \mathrm{~cm}$ seviyesine, $77 \mathrm{~cm}$ 'den $122 \mathrm{~cm}$ seviyesine ve $117 \mathrm{~cm}$ den $158 \mathrm{~cm}$ seviyesine düşmüştür. Piyezometre 7 arazide en hizlı taban suyu tablas düşüş ve yükselişlerin en kısa sürede oluştuğu noktayı göstermektedir. Bu nokta arazinin yüzey eğiminin yöneldiği noktayı temsil etmektedir. Ancak dikey hidrolik eğime bağlı olarak bu piyezometre bataryasının su seviyeleri yer altı suyunu besleme eğilimindedirler. Haziran 2011-Şubat 2012 arası piyezometreler uzun süre kuru kalmış ve bu zaman aralığında yağan toplam $41.3 \mathrm{~cm}$ yağışın (Ekim: $4.72 \mathrm{~cm}$, Kasım: $3.04 \mathrm{~cm}$, Aralık: $11.34 \mathrm{~cm}$ ve Ocak: $22.2 \mathrm{~cm}$ ) eklemeli etkisi 6 Şubat 2012 de bütün piyezometrelerde çok hızlı su seviye yükselişleri olarak görülmeye başlanmıştır (Şekil 7).

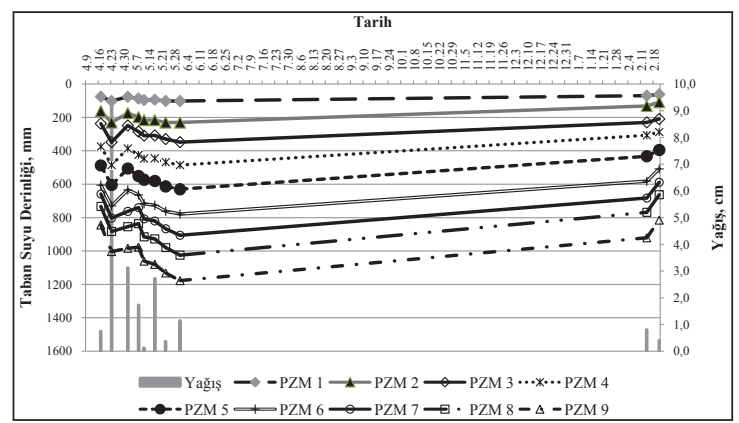

Şekil 7- Araştırma alanında oluşan haftalık yağış̧lar ve piyezometrelerdeki taban suyu seviyeleri

Figure 7- Weekly precipitation events and piyezometric water table depths in the experimental site

\section{Sonuçlar}

Tarladaki tansiyometrelerden toplanan veriler toprakların çok büyük bir kısmının suya doymamış şartlarda olduğunu göstermiştir. Bazı tansiyometreler bulundukları noktada sıfır $\mathrm{kPa}$ (1slak) değerine yakın şartları zamansal olarak gösterseler de her bir tansiyometre için ortalama nem potansiyeli negatif kalmaya devam etmiştir. Gözenek neminin negatif basınçları çok dinamik olup zaman içinde bütün derinliklerde sik sık değişmiştir. Ancak en hızlı değişim 0-30 cm derinliğinde gerçekleşmiştir. Yağışlar boyunca sığ derinliklere gömülmüş tansiyometreler için toprak gözeneklerindeki nemin basıncı çok hızlı bir artış göstermiştir (-16 kPa'dan -3.8 kPa değerine). $\mathrm{Bu}$ durum yüzey toprak derinliklerine gömülü bulunan tansiyometrelerin yağışlara daha hızlı tepki verdiğini ortaya koymaktadır.

Yağışın etkisi ilk $0.3 \mathrm{~m}$ derinlikte görülürken bundan daha derinlerde gözenek neminin basinc1 yağmurdan daha çok hidrolik eğime bağl1 olarak etraftan gelen yeraltı suyu seviyesinin yükselmesinden etkilenmiştir. Yağışlar boyunca toprak nem potansiyelleri $30-60 \mathrm{~cm}$ derinlikte -16 $\mathrm{kPa}$ 'dan $-12 \mathrm{kPa}$ değerine ve $60-90 \mathrm{~cm}$ katmanda $-20 \mathrm{kPa}$ 'dan -10 kPa değerine yükselmiştir. İlk drenaj akışı toprak nem potansiyeli $60-90 \mathrm{~cm}$ katmanda -20 $\mathrm{kPa}$ 'dan $-10 \mathrm{kPa}$ değerine doğru artarken oluşmuştur.

Yağışların sıklığı ve miktarları toprak profilinde suyla doygunluk derecesine yakın değerler (-2 ve -17 $\mathrm{kPa}$ arası) oluşturmasına rağmen toprak drenajı çok gecikmeli olarak (5-7 gün sonra) ortaya çıkmıştır ve drenaj akışları çok düşük debilerle devam etmiştir. Toprak profilinde yukarıdan aşağı su hareketinden (infiltrasyonla gelen su) daha çok taban suyu seviyesindeki dalgalanmalar drenaj akışlarında daha baskın bir rol oynamışlardır. Toprak profilinin killi bir bünyeye sahip olması suyun dikeyde hareketini yavaşlatmış suyun yüzey akışa geçmesini teşvik etmiş ve drenaj olayı sırasında ve drenajdan önce yüzey akışlar oluşmuştur. Drenaj sistemi etkin olarak çalışmasına rağmen toprak profili suyla doygun hale gelebilmektedir. $\mathrm{Bu}$ nedenle kombine drenaj sistemi çalışma alanının drenaj problemini çözmede umut verici bir yaklaşımdır.

Piyezometrelerin hepsi yaz boyunca ve sonbaharda Ekim ortalarına kadar kuru kalmıştır, fakat baharın erken dönemlerinde çok hızlı yükselişler kaydetmişlerdir. $\mathrm{Bu}$ durum için eklemeli yağışların etkisi çok önemli olmuştur. Çünkü eklemeli yağışlar belli bir değere (Aralık için $11.3 \mathrm{~cm}$ ve Ocak için $22.2 \mathrm{~cm}$ ) ulaşınca taban suları ve piyezometrik su seviyeleri çok hızlı yükselmiş, bu eklemeli yağış değerinden küçük yağışlar taban suyunu yükseltici etkide bulunmamıştır. 4-7 günlük bir dönemde yağan eklemeli yağışlar taban suyu seviyelerini piyezometrelerde yaklaşık olarak 32 $\mathrm{cm}$ ve $72 \mathrm{~cm}$ yükseltmişlerdir. Erken kış döneminde taban suyu seviyeleri dalgalı bir seyir izlemiş ancak Mayıs ortasına kadar yüksek kalmayı sürdürmüştür. 
Taban suyu seviyeleri Haziran-Ekim arasinda azalmış, Ekim'den sonra artmaya devam etmiştir. Su seviyelerinin yüzeyden $42 \mathrm{~cm}$ derinde bulunma süresi 22-32 gün sürdürmüştür. Yüksek taban suyu seviyesinin hakim olduğu dönemlerde (Ocak ayı) suyla doygun olmayan katmanın ortalama derinliği $42 \mathrm{~cm}$ olmuştur.

Bu çalışmada piyezometrelerde oluşan su yükü ve piyezometrelerin toprak profilindeki pozisyonlarına dayanarak dikey hidrolik eğim hesaplanmamıştır. Piyezometre bataryası (7-8-9) su seviyesinin çok derinlere inmesi bu bataryadaki suların yer altı suyunu beslediği eğilimini doğurmuştur. Drenaj ile toprak su potansiyeli arasındaki ilişkilerin dren derinliği boyunca modellenerek drenaj sisteminin fonksiyonu ve taban suyu tablası arasındaki ilişkilerin daha detaylı çalışılması gerektiği sonucuna ulaşılmıştır.

\section{Teşekkür}

$\mathrm{Bu}$ proje Mustafa Kemal Üniversitesi Bilimsel Proje Araştırma Birimi (BAP) tarafından iki yıl desteklenmiştir. $\mathrm{Bu}$ çalışmada alet-ekipman ve teşvik edici katkılarından dolayı Prof. Dr. Hüseyin GÖZÜBENLİ, Doç. Dr. Veli UYGUR, Yrd. Doç. Dr. Ömer KONUŞKAN ve Yrd. Doç. Dr. İbrahim ATIŞ'a çok teşekkür ederim. Bu çalışmada en büyük teşekkür araştırma parseli tedarik eden Prof. Dr. Filiz AYANOĞLU'na adanmıştır. Bu çalışmanın tarlaya kurulumundan masa başı çalışmalarına kadar geçen süreçte Sn. Burhan DURGUN ve Burak DURGUN'a değerli katkılarından dolayı çok teşekkür ederim.

\section{Kaynaklar}

Bradley C, Mosugu M \& Gerrard J (2007). Seasonal dynamics of soil water pressure in a cracking clay soil. Catena 69: 253-263

Bradley C, Clay A, Clifford N J, Gerrard J \& Gurnell A M (2010). Variations in saturated and unsaturated water movement through an upland floodplain wetland, mid-Whales, UK, Journal of Hydrology 393: 349-361

Brooks R H \& Corey A T (1964). Hydraulic properties of porous media. Hydrology paper 3. Colorado State University, Fort Collins, CO

Campbell G S (1988). Soil water potential measurement: an overview. Irrigation Science 9: 265-273

Cassel D K \& Klute A(1986). Water potential: tensiometry. In: Klute, A. Ed.., Methods of Soil Analysis: Part 1. Physical and Mineralogical Methods. Monograph No. 3, American Society Agronomy, Madison, WI, pp. 563-596
Cuny H, Wery J \& Gaufres F (1998). A simple indicator for diagnosing leaching risk below the root zone using Tensionic tensiometers. Agronomy Journal 18: 521-535

Dane J H, Walker R H, Bahaminyakamwe L \& Belcher J L (2006). Tall fescue and hybrid bluegrass response to soil water matric head limits. Agricultural Water Management 86: 177-186

DSİ (Office of Turkish Hydraulic Works) (1962). Amik projesi: Amik Ovası Planlama Arazi Tasnif Raporu. T.C. Bayındırlık Bakanlığı Devlet Su İşleri Genel Müdürlüğü Etüt ve Plan Dairesi Reisliği, Etüt Raporları No: 17-104, Proje No: 1901, Ankara

Gaudin R \& Rapanoelina M (2003). Irrigation based on a nomogram using soil suction measurements. Agricultural Water Management 58: 45-53

Lim T T, Rahardjo H, Chang M F \& Fredlund D G (1996). Effect of rainfall on matric suctions in a residual soil slope. Canadian Geotechnical Journal 33: 618-628

Martin R P, Siu K L \& Premchitt J (1994). Review of the performance of horizontal drains in Hong Kong. Special Project Report, SPR 11/94, Geotechnical Engineering Office, Civil Engineering Department, Hong Kong, pp. 106

Rahardjio H, Hritzuk K J, Leong E C \& Rezaur R B (2003). Effectiveness of horizontal drains for slope stability. Engineering Geology 69: 295-308

Richards L A (1949). Methods of measuring soil moisture tension. Soil Science Society of America 68: 95-112

Silber A, Levi M, Cohen M, David N, Shtaynmetz Y \& Assouline S (2006). 'Safari Sunset' response to irrigation and fertilization levels. The Journal of Horticultural Science and Biotechnology 81: 335-364

Silber A, Levi M, Cohen M, David N, Shtaynmetz Y \& Assouline S (2007). Response of Leucadendron 'Safari Sunset' to egulated deficit irrigation: Effects of stress timing on growth and yield quality. Agricultural Water Management 87: 162-170

USSLS (1954). Diagnosis and Improvement of Saline and Alkali Soils. Agriculture Handbook 60. USDA. Reprinted 1969. U.S. Government Printing Office, Washington D.C

Wang F X, Kang Y, Liu S P \& Hou X Y (2007). Effects of soll matric potential on potato growth under drip irrigation in the North Chana Plain. Agricultural Water Management 88: 34-42

Wery J (2005). Differential effects of soil water deficit on the basic plant functions and their significance to analyse crop responses to water deficit in indeterminate plants. Australian Journal of Agricultural Research 56: 1201-1209

Young M H \& Sisson J B (2002). 3.2. Water Potential, 3.2.2. Tensiometry. In: Dane, J.H., Topp, G.C. (Eds.), Methods of Soil Analysis. Part 4. Physical Methods. Soil Sci. Soc. Am. Book Series No. 5. Madison, WI, pp. 575-608 